\title{
A Study on Intestinal Parasitic Infections Among Immunocompetent Egyptian Children Attending Al-Hussein University Hospital, Cairo
}

\author{
Morsy R. Geneidy
}

Medical Parasitology Department, Faculty of Medicine (Boys), Al-Azhar University, Cairo, Egypt

\begin{abstract}
Background: Parasitic infections are still a dangerous public health problem in the world, especially in developing countries including Egypt representing a major cause of morbidity and mortality mainly among children.

Methods: This cross-sectional study included 400 randomly chosen immunocompetent children of both sexes. Their ages ranged from 6 months up to 12 years old. All children were subjected to a structured questionnaire sheet, stool examination using: Direct smear and concentration techniques (formol ether sedimentation and Modified Ziehl-Neelsen stain). The study was approved by the medical ethics committee of Al-Azhar University Hospitals and a written informed consent was obtained from all children's parents or gardeners.

Results: Among the examined individuals, parasites were detected in only 139 ones (34.75\%) mainly in the first two years of age and more common among males 35\% than females 34\%. By species, the parasitic prevalence rate was, G.lamblia 49 (12.25\%), E.vermicularis 35 (8.75\%), E. coli 22 (5.5\%), E. histolytica/dispar 7 (1.75\%), H. nana $4(1.0 \%)$ and mixed infections $22(5.5 \%)$. Positive results are more common among rural children $38 \%$ and low social classes. Low level of parent's education, low family income, high crowding index, and bad hand hygiene were considered highrisk factors of parasitic infections. Conclusion: Rural residency, bad hygiene, and low social class, as well as crowdedness, were the most significant risk factors associated with parasitic infections among children
\end{abstract}

Keywords: Immunocompetent children, Intestinal parasites, Egypt.

\section{INTRODUCTION}

Intestinal parasitic infections are considered a serious public health problem all over the world, especially in developing countries including Egypt. They considered as a major cause of morbidity and mortality in childhood because they cause malnutrition, iron deficiency anemia, growth retardation as well as other physical and mental problems ${ }^{(\mathbf{1})}$.

They are considered as one of the most common infections worldwide where 3.5 billion peoples are infected with some kinds of intestinal parasites ${ }^{(2)}$.

School children represent a high-risk group for parasitic infections due to the facility of direct interpersonal contact ${ }^{(3)}$. The prevalence of infections depends on the socioeconomic level of the society, poor sanitation and environmental conditions, inadequate personal hygiene and absence of clean drinking water supplies as well as climatic factors ${ }^{(4)}$. Also, the lack of awareness about the mode of infection and transmission of parasitic infections increases the risk of infection. So that, a better understanding of the previous factors, as well as how social, cultural and behavioral awareness affect the epidemiology and control of intestinal parasitic infections may help to design a good and effective control guideline of these infections ${ }^{(5)}$.

The aim of this work: was to determine the intestinal parasitic profile among immunocompetent children presented with diarrhea or other gastrointestinal manifestations who attended Al-Hussein University Hospital.

\section{SUBJECTS AND METHODS}

A cross-sectional study was carried out from October 2017 to December 2018 and included 400 immunocompetent children of both sexes presented with diarrhea or other gastrointestinal manifestations. Their ages ranged from 6 months up to 12 years old and they attended the outpatient Clinics of Pediatrics, Al-Hussein University Hospital, Cairo, Egypt.

\section{Inclusion criteria}

Immunocompetent infants and children aged 6 months up to 12 years old of both sexes.

\section{Exclusion criteria}

Children with diarrhea associated with other illnesses like hepatitis, respiratory infection, lactose intolerance and surgical conditions like appendicitis and immunocompromised children.

\section{Ethical approval:}

The study was approved by the medical ethics committee of Al-Azhar University Hospitals and a written informed consent is obtained from all children's parents or gardeners.

All the studied patients were subjected to the following:

1- Structured questionnaire.

2- General and abdominal clinical examination.

3- Examination of a perianal specimen for pinworm eggs or Taenia egg or gravid segments.

4- Stool examination: -

Fresh fecal specimens were collected from all patients in clean labeled, dry disposable plastic cups. They were examined as soon as they received by the naked eye for consistency, presence of adult worms, blood or mucus. Liquid or watery stool specimens were examined first followed by semi-formed stool specimens. Stool samples were examined by:

A- Direct wet mount method: ${ }^{(6)}$.

B- Formol ether concentration ${ }^{(6)}$. 
C- Modified Ziehl-Neelsen stain (Hot technique): ${ }^{(7)}$.

\section{Statistical analysis of data}

The collected data were revised, coded and entered into a personal computer (PC), where statistical analysis was done using the statistical program (SPSS) Statistical Package for Social Science Version 20 for windows and Graph pad instant.

Descriptive statistics were:

- Frequencies and percentage for qualitative data.

- Analytical statistics were done using the Chi-square test for comparison of $2 \times 2$ or more tables of qualitative data.

- The P-value of used statistical tests 0.05 or less was considered significant and below 0.001 highly significant.
Anthropometric assessment. To classify the nutritional status of children, the weight-for-height index was used due to its simplicity in the detection of malnutrition in the field study. Nutritional status was divided into six categories: obese $120 \%$, overweight $110-120 \%$; normal good nutrition, 90-109\%; mild malnutrition, 80-89\%; moderate malnutrition $70-79 \%$ and severe malnutrition $70 \%{ }^{(8)}$.

\section{RESULTS}

The demographic data for all patients were presented in Table 1.

Table (1): Demographic data of all the patients

\begin{tabular}{|c|c|c|c|}
\hline \multirow{2}{*}{\multicolumn{2}{|c|}{ Characteristics }} & \multicolumn{2}{|c|}{ Total (400) } \\
\hline & & No & $\%$ \\
\hline \multirow{3}{*}{ Age } & $0.5-2$ years & 130 & $32.9 \%$ \\
\hline & $>2-5$ years & 212 & $53.2 \%$ \\
\hline & $>5-12$ years & 58 & $14.7 \%$ \\
\hline \multirow{2}{*}{ Sex } & Males & 224 & $56 \%$ \\
\hline & Females & 176 & $44 \%$ \\
\hline \multirow{2}{*}{ Residence } & Rural & 90 & $22.5 \%$ \\
\hline & Urban & 310 & $77.5 \%$ \\
\hline \multirow{4}{*}{ Social classification } & Very low social standers & 33 & $8.3 \%$ \\
\hline & Low social standers & 149 & $37.3 \%$ \\
\hline & Middle social standers & 131 & $32.8 \%$ \\
\hline & High social standers & 87 & $21.8 \%$ \\
\hline \multirow{5}{*}{ Education of the father } & Read and write or illiterate & 65 & $16.3 \%$ \\
\hline & Primary education & 25 & $6.3 \%$ \\
\hline & Preparatory education & 76 & $19.0 \%$ \\
\hline & Secondary education & 190 & $47.5 \%$ \\
\hline & University or higher & 44 & $11.0 \%$ \\
\hline \multirow{7}{*}{$\begin{array}{l}\text { Education and the work } \\
\text { of the mother }\end{array}$} & Read and write or illiterate not working & 62 & $15.5 \%$ \\
\hline & Primary education not working & 27 & $6.8 \%$ \\
\hline & Preparatory education not working & 64 & $16.0 \%$ \\
\hline & Secondary education not working & 156 & $39.0 \%$ \\
\hline & Secondary education working & 54 & $13.5 \%$ \\
\hline & University education not working & 31 & $7.8 \%$ \\
\hline & University education working & 6 & $1.5 \%$ \\
\hline \multirow[b]{3}{*}{ Income } & Average income is usually less than demands & 84 & $21.0 \%$ \\
\hline & Average income is just satisfactory & 206 & $51.5 \%$ \\
\hline & Average income is beyond usual demands & 110 & $27.5 \%$ \\
\hline \multirow{3}{*}{ Crowding index } & 2 or less/ room & 167 & $41.8 \%$ \\
\hline & 3/room & 201 & $50.2 \%$ \\
\hline & $4 /$ room & 32 & $8.0 \%$ \\
\hline \multirow[b]{2}{*}{ Sanitation } & electricity and special water closets & 16 & $4.0 \%$ \\
\hline & $\begin{array}{l}\text { pure water supply, electricity, and special } \\
\text { water closets }\end{array}$ & 384 & $96.0 \%$ \\
\hline \multirow{5}{*}{ Presentation } & Diarrhea & 254 & $63.5 \%$ \\
\hline & Anorexia & 227 & $56.8 \%$ \\
\hline & Vomiting & 153 & $38.3 \%$ \\
\hline & Perianal itching & 121 & $30.3 \%$ \\
\hline & Abdominal pain & 64 & $16.0 \%$ \\
\hline
\end{tabular}


ejhm.journals.ekb.eg

Among the examined 400 individuals, parasites were detected in only 139 ones with overall prevalence (34.75\%)

Figure 1.

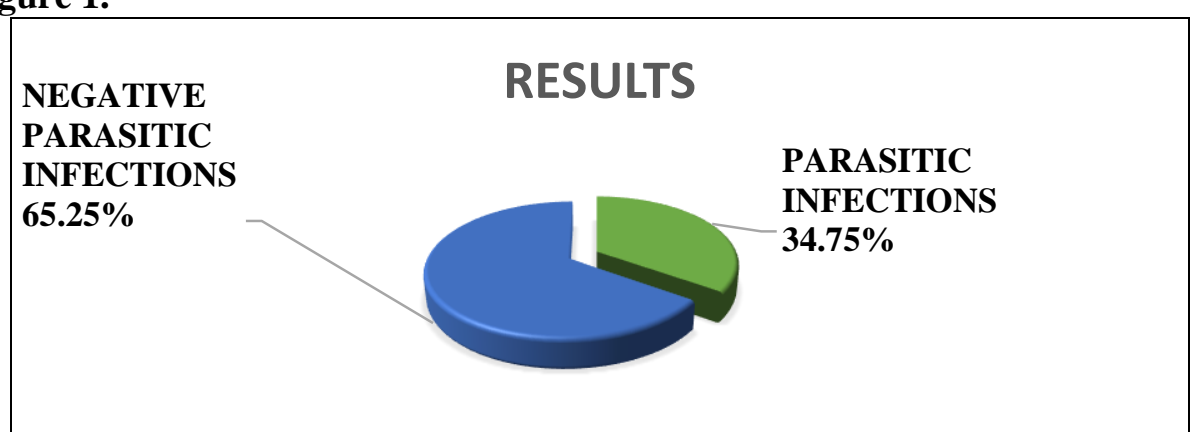

\section{Fig (1): Prevalence of parasitic infections}

By species, the rate for different intestinal parasitic infections was as follows: Giardia lamblia 49 (12.25\%), Enterobius 35 (8.75\%), E. coli 22 (5.5\%), E. histolytica/dispar 7 (1.75\%), H. nana 4 (1.0\%) and mixed infections 22 $(5.5 \%)$ Figure 2.

Mixed infections were as follows: Giardia + Entamoeba coli 8 (2\%), Giardia + Enterobius 7 (1.75\%), Entamoeba histolytica/dispar + Enterobius $4(1 \%)$, Giardia lamblia + Entamoeba histolyticaldispar $2(0.5 \%)$ and Giardia + Enterobius + H. nana $1(0.25 \%)$.

The most frequent complaint among the infected children was diarrhea (63.5\%), followed by anorexia (56.8\%); then vomiting (38.3\%) and lastly perianal itching (30.3\%) and abdominal pain (16\%).

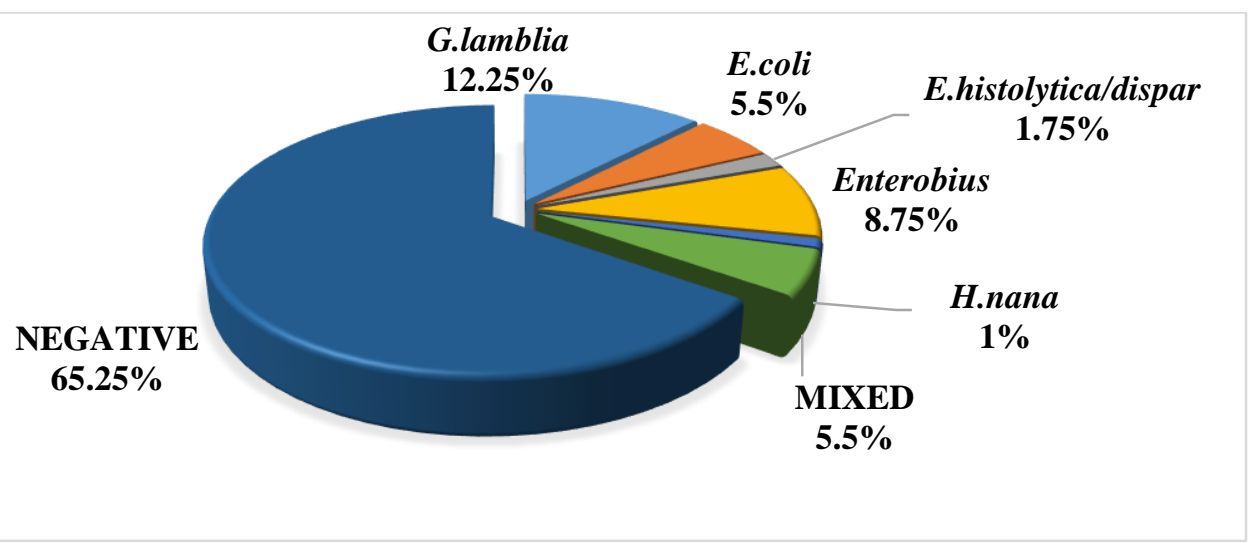

Fig (2): The frequency of parasitic infections among the infected cases

As regard the age factor, we found more infections among the first two years than the school-age children which is statistically nonsignificant Figure 3. As regards the sex factor, we found the more positive results were in males 35\% than females 34\% which was statistically nonsignificant Figure 4.

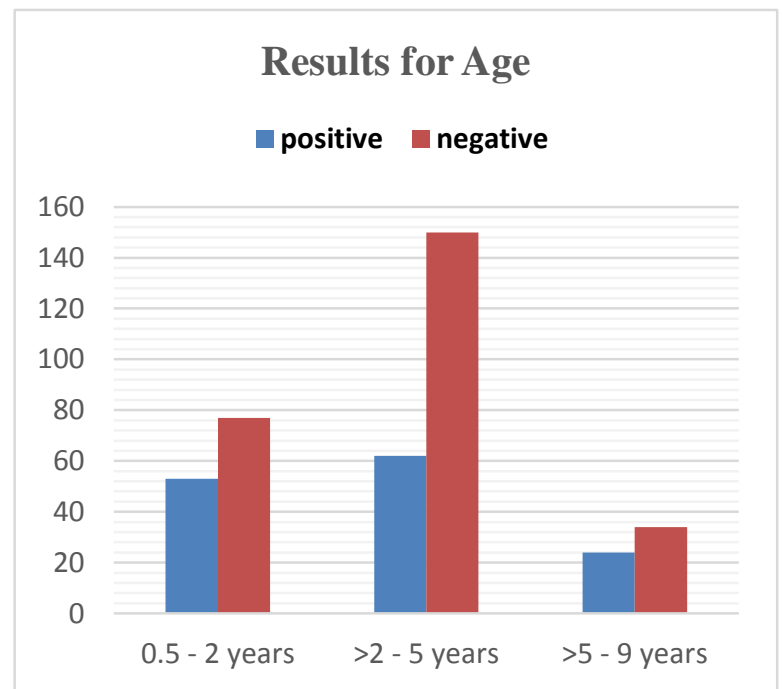

Fig (3): The results for age

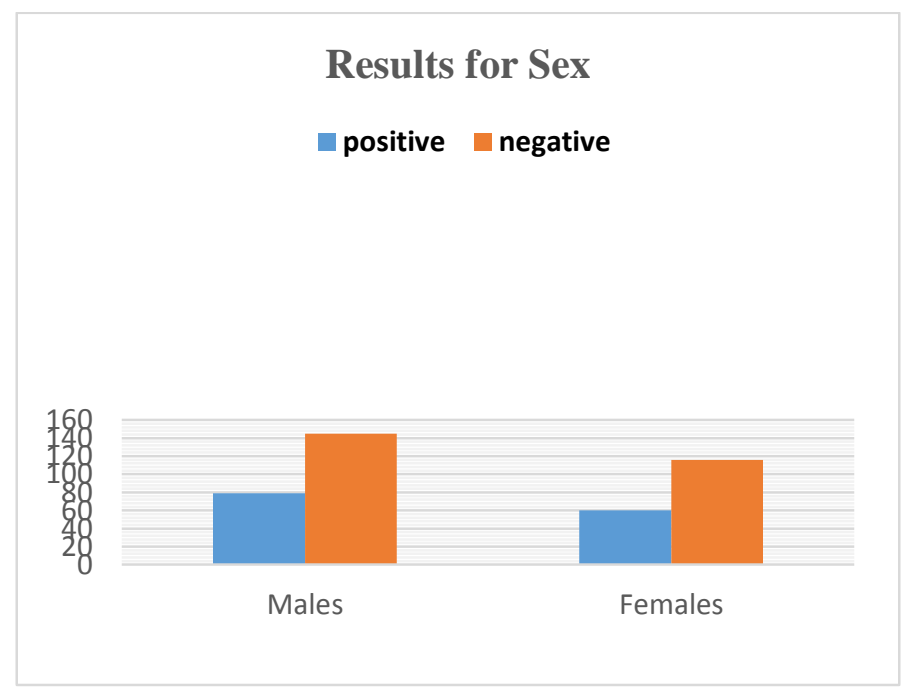

Fig (4): The results for sex 
Regarding residence, more positive results were found in rural 38\% than in urban areas $34 \%$ which was statistically nonsignificant Figure 5. Regarding sociodemographic risk factors, the low social classes were a highly statistically significant risk factors for parasitic infections Figure 6.

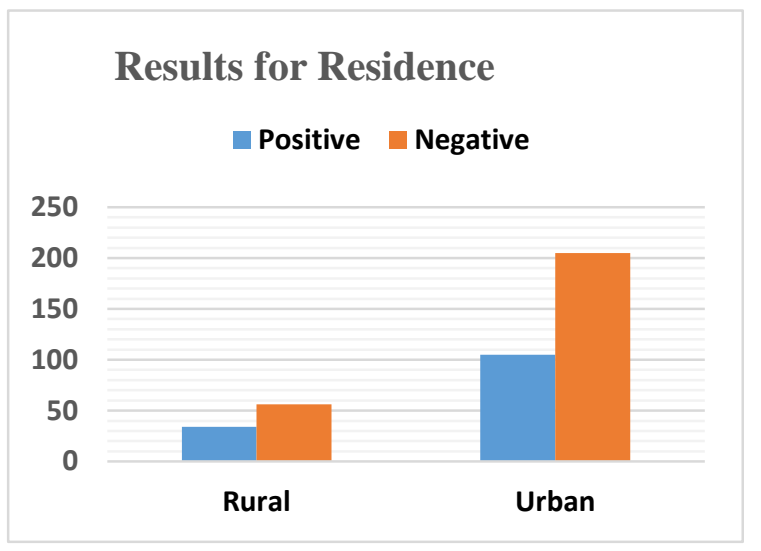

Fig (5): The results for residence

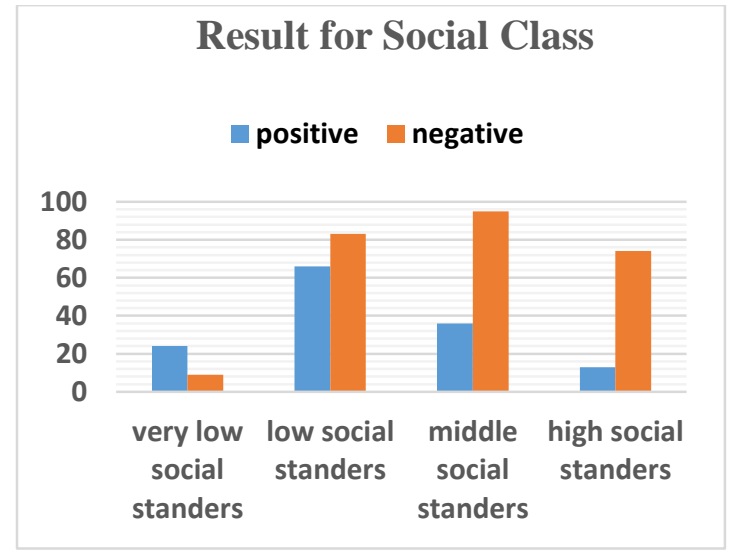

Fig (6): The results for social class

Besides, the low level of parent's education and working were highly significant risk factors for parasitic infections.

Also, the low income of the family, as well as the high crowding index, were considered as a highly significant risk factors Figure 7. Bad hand hygiene was highly significant risk factor for parasitic infections Figure 8.

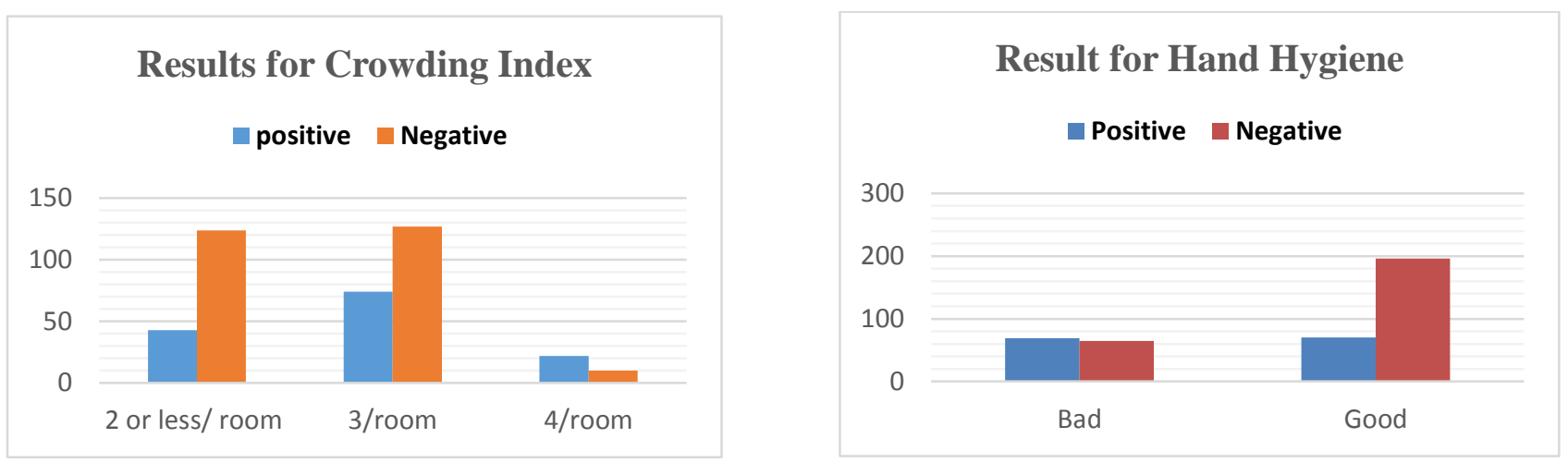

Fig (7): The results of crowding index

Fig (8): The results of hand hygiene

There is no significant correlation between parasitic infections and the nutritional status of the infected children Table 2.

Table (2): The relation between parasitic infections and nutritional status

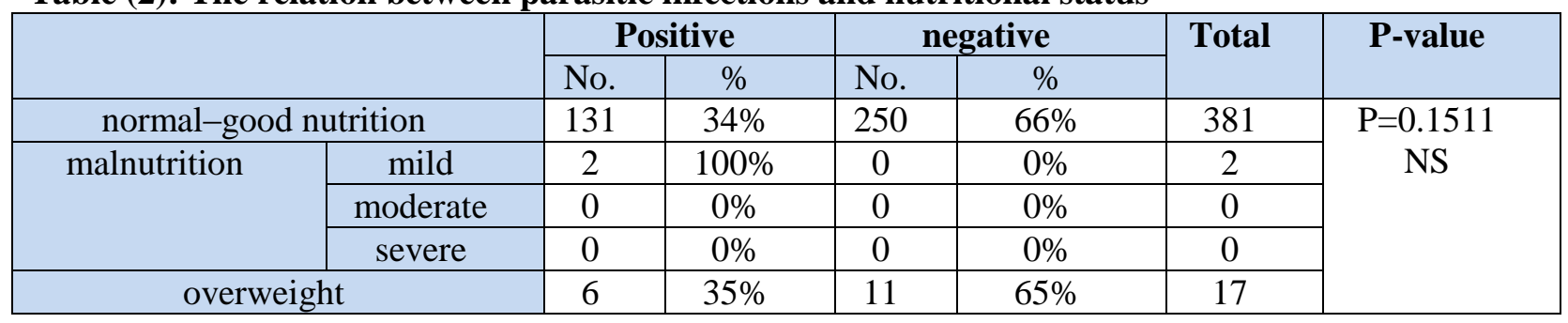

\section{DISCUSSION}

Morbidity due to intestinal parasitic infections is considered as an important public health problem in the tropics, but the incidence and severity may vary depending on the location and time of examination. Moreover, the differences in the prevalence rate may be due to the use of different diagnostic procedures and the difficulties involved in the identification of certain parasites as well as the experience of the technicians ${ }^{(9)}$.

In the present work, it was found that approximately one-third (34.75\%) of the children, aged 0.5 to 12 years, in Cairo were infected by intestinal parasites. This was nearly coincided with El-Gammal et al. ${ }^{(10)}$, Kamal and Nofal ${ }^{(11)}$ and Mohammad et al. ${ }^{(12)}$ who reported that the prevalence of parasitic infections between Egyptian school children in Malames village in Lower Egypt was $31.9 \%$ while $33.5 \%$ and $30.7 \%$ were among school children in Alexandria and Damietta respectively.

However, our results were slightly lower than that reported by El-Masry et al. ${ }^{(13)}$ and Bayoumy et al. ${ }^{(14,15)}$ who found that $(38.5 \%),(39.1 \%)$ and $(38.3 \%)$ of school children in villages at Tahta District, Sohag, El Wadi El 
Gadeed, and Behera Governorates had intestinal parasitic infections, respectively.

The present results were also less than obtained by Mousa et al. ${ }^{\left({ }^{(16)}\right.}$ who reported a parasitic infection rate of (60.9\%) from different areas in Great Cairo. Also, higher results were obtained by Hegazy et al. ${ }^{(17)}$ and Younes $\boldsymbol{e t}$ al. ${ }^{(18)}$ who found prevalence rates of $(51.8 \%),(55.7 \%)$ and in Behera and Assiut Governorates.

This difference of results can be attributed to the difference in socioeconomic standards, health education, personal hygiene, and human excreta sanitary disposal among the examined localities.

The prevalence rate of infection was (67\%) for protozoal and (33\%) for helminthic infections and distributed as following: Giardia lamblia (12.25\%), Entamoeba coli (5.5\%), Entamoeba histolytica/dispar $(1.75 \%)$, Enterobius vermicularis $(8.75 \%)$ and Hymenolepis nana (1\%) while mixed infections reached $(5.5 \%)$.

Giardia lamblia was the commonest protozoan parasite detected $(12.25 \%)$ which coincided with that reported by Ward ${ }^{(19)}$. Also, Chacon-Cruz and Mitchell (20) reported that $G$. lamblia is the most commonly isolated intestinal parasite all over the world with prevalence rates ranged between $20-40 \%$. The prevalence rate of Entamoeba coli reached (5.5\%) while Entamoeba histolytica/disbar was less frequent (1.75\%). Its prevalence varies in different countries and is common in underdeveloped countries where amoebiasis is considered the third important cause of death and about $(10 \%)$ of the world population is estimated to be infected with that parasite ${ }^{(21)}$. Both remain the most common intestinal parasitic pathogens transmitted via the fecaloral route either directly from person to person or indirectly by eating or drinking contaminated food and water ${ }^{(12)}$. The differences of prevalence in different locations may be attributed to different levels of sanitation, types of water supply, hygienic measures and food behaviors ${ }^{(22)}$.

E. vermicularis was the highest helminthic parasite found among all the examined children $8.75 \%$ which coincided with El-Masry $\boldsymbol{e t}$ al. ${ }^{(13)}$ and Bayoumy $\boldsymbol{e t}$ al. (14) while $H$. nana was $1 \%$. Both are characterized by transmission secondary to contamination of the hands and can cause autoinfection indicating the role of personal hygiene including handwashing with soap after defecation and before eating or preparing food as well as contact with infected persons or animals either in the school or within their families ${ }^{(23)}$.

Mixed infection constitutes $(5.5 \%)$ of the infected cases. The most common double infection was as follows: Giardia + Entamoeba coli 8 (2\%), Giardia + Enterobius 7(1.75\%), Entamoeba histolytica/dispar + Enterobius 4 (1\%), Giardia lamblia + Entamoeba histolyticaldispar $2(0.5 \%)$ and Giardia + Enterobius + H. nana $1(0.25 \%)$. The present results had coincided with
Monib et al. ${ }^{(24)}$ in Assiut Governorate who recorded $(7.3 \%)$ as a prevalence rate for mixed double infections.

Gender seemed not to be a factor affecting the parasitic infection rate. But, Oluwafemi ${ }^{(25)}$ showed that some parasitic infections as E. histolytica/dispar were higher in girls than boys, and Ascaris lumbricoides was higher in boys.

The present results showed that the frequency of parasitic infections was higher among rural (38\%) compared to urban inhabitants (34\%) despite the majority of examined children were urban $(77.5 \%)$ which may explain the relatively low overall prevalence of parasitic rate. This may be because rural areas, in general, are characterized by low socioeconomic and educational levels, which favor the transmission of parasitic infections. Also, higher rates were reported by Bakr $\boldsymbol{e t}$ al. ${ }^{\text {(26) }}$ from rural areas in Monofeya Governorate (47.8\%) and $(53.4 \%)$ was reported by El-Beshbishi et al. ${ }^{(27)}$ from rural areas in Dakahlia Governorate.

Lower socioeconomic status is also a risk factor for intestinal parasites with high significance. These coincided with El-Gammal $\boldsymbol{e t}$ al. ${ }^{\left({ }^{(10)}\right.}$ who reported that $43.0 \%$ of their students were belonging to low socioeconomic standards in Lower Egypt.

Also, the low level of parents education and work were highly significant risk factors for parasitic infections. Besides, the low income and high crowding index were highly significant risk factors for parasitic infections. In general, parasitic infections are more prevalent under crowded conditions ${ }^{(27)}$.

Also, bad hand hygiene was a highly significant risk factor for parasitic infections. Handwashing with soap removes potentially pathogenic organisms. It was found in this work that the most of infected children did not wash their hands regularly with soap. Similar results were obtained in a study among Turkish schoolchildren ${ }^{(28)}$. Mohammad et al. ${ }^{(12)}$ agreed with our results in that poor personal hygiene encourages person-to-person transmission, and poor food handling hygienic measures, presence of flies and cockroaches as vectors of transmission of infection and contaminated water. We could not determine any association between the anthropometric indices and intestinal parasites and there is a discrepancy in the available literature on this question as some studies reported a positive association as Bethony et al. ${ }^{\left({ }^{29)}\right.}$ whereas others reported no association as Lunn et al. ${ }^{(30)}$.

\section{CONCLUSION}

Although the prevalence rates of reported parasitic infections in the present study were nearly comparable with similar studies conducted in other parts of Egypt, the rate of infection is, however, of public health importance. So, it is recommended for early identification of clinical manifestations that may help in the early detection and treatment of infections. Also, necessary sanitary strategies, health education, improving socio-economic 
conditions, improving of personal hygienic measures including safe food and drink supplies, regular screening and treatment for parasitic infections must be in mind as control measures for parasitic infections.

\section{REFERENCES}

1- Hill DR (2007): Giardia lamblia. In: Principles and Practice of Infectious Diseases. Mandell GL, Bennett JE, Dolin R. (Eds). New York: Churchill Livingstone.

2- World Health Organization (2001): Fifty-fourth World Health Assembly. Assembly documents. Provisional agenda item 13.3: Communicable diseases. Control of Schistosomiasis and soiltransmitted helminth infections. Report by the Secretariat, Geneva.

3- Carvalho TB, Carvalho LR, Mascarini LM (2006): Occurrence of enteroparasites in day care centers in Botucatu (São Paulo State, Brazil) with emphasis on Cryptosporidium parvum and Enterobius vermicularis. Rev Inst Med Trop Sao Paulo, 48: 269-273.

4- Kvalsvig JD (2003): Parasites, nutrition, child development, and public policy. In: Controlling Disease due to Helminth Infections. Crompton DWT, Montresor A, Nesheim MC, Savioli L. (Eds). Geneva: World Health Organization.

5- Mahmoud AM, Abdul Fattah M, Zaher TI, Abdel-Rahman SA, Mosaad N (2017): Intestinal parasitic infections and iron deficiency anemia among school children in El Khalige Village, Dakhalia, Egypt. Afro-Egypt J. Infect. Endem. Dis., 7(1):28-36.

6- World Health Organization (WHO) 1991: Basic laboratory methods in medical parasitology.

7- Garcia LS (2007): Intestinal protozoa (Coccidia and Microsporidia) and Algae in (Diagnostic Medical Parasitology). Fifth edition (Garcia, L. S.ed.). ASM (American Society for microbiology) Press.

8- Hill KF (2003): Work for studying the determinants of child survival (Online). http//.whqlibdoc.who.int/bulletin/2003/Vol81 138-39.

9- Sethi S, Sehgal R, Malla N, Mahajan RC (1999): Cryptosporidiosis in a tertiary care hospital. Natl Med J India, 12: 207-9

10-El-Gammal N, Sayed El-Ahl S, Osman FH, Salem HS (1995): Comparative study of parasitic infections among school children in two rural areas in Upper Egypt (Demo village) and Lower Egypt (Malames village). The Egypt J Comm Med., 3 (1): 25-30.

11-Kamal NA, Nofal LM (2012): Anthropometric status, anemia and intestinal parasitic infections among primary school children in Alexandria, Egypt. Bull. of High Inst. of Pub. health, 42:82-102.

12-Mohammad KA, Abu El-Nour MF, Saad MY, Timsah AG (2012): The prevalence and associated risk factors of intestinal parasitic infections among school children living in rural and urban communities in Damietta Governorate, Egypt. Academ Arena, 4:90-97

13-El-Masry HM, Ahmed YA, Hassan AA, Zaky S, Abd-Allah ES (2007): Prevalence, risk factors, and impacts of schistosomal and intestinal parasitic infections among rural school children in Sohag Governorate. The Egypt. J. Hosp. Med., 29: 616-630.

14-Bayoumy AMS, Ibrahim WLF, Abou EL-Nour BM, Said AA (2016): The Parasitic profile among school children in El-Wadi ElGadded Governorate, Egypt. J. Egypt. Soc. Parasitol., 46: 605-612
15-Bayoumy AMS, Abd EI Raheem MA, Abo Hashim, A, Saadawy AS, Al Karyony IM (2018): Parasitic profile among primary school children in a rural area at Behera Governorate, Egypt. The Egypt. J. of Hosp. Med., 70 (12): 2042-2049

16-Mousa KM, Abdel-Tawab AH, Khalil HH, El-Hussieny NA (2010): Diarrhea due to parasites particularly Cryptosporidium parvum in great Cairo, Egypt. J Egypt Soc. Parasit., 40(2): 439-50.

17-Hegazy AM, Aminou HA, Badr AM (2014): Prevalence of intestinal parasites and its impact on nutritional status among preschool children living in Damanhur City, Beheira Governorate, Egypt. J. Egypt. Soc. Parasitol., 44: 517-24.

18-Younes DA, Galal LA, Abdallah AM, Zaghlol KS (2015): Effect of enteric parasitic infection on serum trace elements and nutritional status in upper Egyptian children. Trop. Parasitol., 5: 29-35.

19-Ward HD (2009): Intestinal protozoan parasites and diarrheal diseases in Bangladesh. Clin. Infect. Dis., 48:1198-1200.

20-Chacon-Cruz E, Mitchell DK (2009): Intestinal protozoal disease. E-Medicine Pediatrics. General Medicine.

http://www.emedicine.medscape.com/article/999282-Overview.

21-Wadood AU, Abdul Bari A, Qasim KF (2005): Frequency of intestinal parasitic infection in Children Hospital Quetta. Pakistan J. Med. Res., 44:2.

22-Bauomy AM, Hamed AM, Abdelaziz N HR, Abdeltawab AH, Monazea EM, Abd Elkreem HE, Mohamed SA (2010): Prevalence and risk factors associated with worm infestation in school-aged children in Al-Azhar and Assiut University Hospitals. Al-Azhar Assuit Med J., 8: 88-106.

23-Metawea AGS (2016): Effect of intestinal parasites on hematological parameters in school-age children in Gharbia Governorate, Egypt. M.Sc. Thesis in Medical Parasitology, AlAzhar University, Egypt.

24-Monib ME, Hassan AA, Attia RAH, Khalifa MM (2016): Prevalence of intestinal parasites among children attending Assiut University Children's Hospital, Assiut, Egypt. J. Adv. Parasitol., 3 : $125-131$.

25-Oluwafemi O (2003): Parasitic infestation and anemia: The prevalence in a rural hospital setting. J Indian Acad Clin Med., 4 (3): 281-7.

26- Bakr IM, Arafa NA, Ahmed MA, Mostafa M H, Mohamed MK (2009): Prevalence of intestinal parasitosis in a rural population in Egypt, and its relation to socio-demographic characteristics. J. Egypt. Soc. Parasitology,39(1):371-381.

27-El-Beshbishi SN, Abdel-Magied AA, El-Nahas HA, Azab MS, El-Shazly AM, Morsy AT, Gamal-Edin M, El-Kadi M (2005): Geoparasites in rural Dakahlia Governorate, a preliminary based study for the development of the community-based intervention programs. J. Egypt. Soc. Parasitol.,35(3):1051-1070

28-Östan I, Kilimcio lu AA, Girginkarde ler N, Özyurt CB, Limoncu ME, Ok UZ (2007): Health inequities: lower socioeconomic conditions and higher incidences of intestinal parasites. BMC Pub Health,7: 342-50.

29-Bethony J, Brooker S, Albonico M, Geiger SM, Loukas A, Diemert D, Hotez PJ (2006): Soil-transmitted helminth infections: ascariasis, trichuriasis, and hookworm. Lancet,367: 1521-1532.

30-Lunn PG, Erinoso HO, Northrop-Clewes CA, Boyce SA (1999): Giardia intestinalis is unlikely to be a major cause of the poor growth of rural Gambian infants. J Nutr., 129: 872-877. 